\title{
Editorial
}

\section{Lessons From The History of Medical Science}

\author{
DOI: https://doi.org/10.3329/kyamcj.v10i2.42780
}

Modern world is a product of past events of creation and evolution. If we look into the insight of our original climates and cultures of the past, we will be aware of cross-cultural similarities and dissimilarities that would positively enlighten our vision towards excellence. If a particular decision in a particular situation by our forefathers had been proved successful, we can take similar decision in that particular situation. Similarly if another particular decision in another particular situation by our forefathers had been proved unsuccessful, we can avoid that, thus to reduce our mistakes. If one doesn't know the history, one is regarded as to know nothing. The history is a reply of unquoted queries. ${ }^{1}$ The past is a 'blessing' and a 'lesson' as well for the learners. History is filled up with good, better, the best, ugly, uglier, the ugliest, bad, worse, the worst past human acts, behaviors, interactions, perceptions and thoughts about life, demography, sociology and science. Knowing history, we can focus our light into human psychology to a deeper extent that inevitably aids us in managing patients better and planning the future. History is a continuum of learning process by 'TRY, ERROR, REPEAT' until one learns what to do and what not to do that are being evolved from the 'past' to the 'future' through the 'present'. This is equally true for our medical science. Learning from the 'past' helps us in the 'present' and the 'future' as well. Thinkings change over time. ${ }^{3}$ The past history makes one analyze and makes one think over the right or wrong things. Keeping these thinking's in the loop of experiences, one can face the obstacles and hurdles with more enhanced maturity, force and equipments. ${ }^{2}$ Thus the decoded 'past' assists the 'present' and sharpens the 'future'. For realizing and assessing the values of the 'present', one has to learn from the 'past'. And the 'present' knowledge based on the 'past' aids in formulating the optimum expected changes for 'the presumed best future'. The 'past' is a teacher of the 'present'. And both the 'past' and the 'present' are the teachers of the 'future'. For example, by knowing and studying the history of nuclear bomb explosion at Hiroshima and Nagasaki in Japan or the Chernobyl nuclear disaster at Ukraine in the then USSR, We can take preventive global political and scientific measures so that no more similar disastrous incidents can occur again. ${ }^{4}$ And now we can more easily and efficiently diagnose and treat the affected people of this kind of disasters. In addition, we can undertake the best possible measures to reduce the number of casualties to minimum and the affected people gets early prompt adequate efficient effective and the most modern Avant-grade medical care. If one doesn't know one's own history, one is just like a blind person or an irrational animal. Then one can't affix one's own targets and peaks to be dreamt and achieved, one can't correct one's own mistakes comparing with the ones of previous history, one can repeat the mistakes done by the ancestors, and even one doesn't affix the right point wherefrom one should start one's own, community and professional journeys. Thus knowing the past history well, one can move forward from the present status with nearly minimal mistakes paving the path of journey through an acceptable right vista towards anticipated targets and peaks of excellence of truth, beauty and facts. ${ }^{5}$ Thus we should learn well from the history of medical science and its branches, the super specialties, the sub specialties and also we should try utmost to unveil the prehistoric facts of medical science as far as feasible from the relics, the remnants, the fossils and the paintings etc. Our ancestors used various compounds, animal and plant products like mercurial and arsenical complexes, honey, nectar, alovera, similar other compounds and extracts as panacea and remedies for a myriad of known and unknown illnesses. ${ }^{6}$ We can just follow them to identify more and more specific ingredients within those medicinal items that are of utmost valuable as more and more specific subtle remedies for today's defined illnesses. We can now define the historic illnesses more specifically and scientifically. Our forefathers of medical science had laid the foundation of tenet of basic methods how to treat and behave with the patients and their attendants. ${ }^{7}$ For improving the quality of modern health care, we need to follow them as relevant. Overlooking the historical perspectives, if we remain tied and bound with the modern technologies only, we will miss every opportunity to offer better alternatives that could improve our patients' quality of life and health. If we are not aware of the past mistakes, we will be repetitively making the same mistakes, doing unexpected harms to our patients. ${ }^{8}$

The history of medical science is very long, enriched, and filled up with myths and stories about how people helped others with illnesses and injuries. Inevitably, the ways from the earliest measures to treat ailments to today's Avant-grade medical care are hurdled with misjudges, maltreatments and mistakes. ${ }^{9}$ But it is also adorned with brilliant thoughts, ideas, dramatic inventions and procedures like discovery of penicillin by Alexander Fleming in 1928, successful leg transplantation in the year $300 \mathrm{AD}$ by Christian Arabian twin saints St. Cosmas and St. Damian, successful repair of a beating heart wound in Montgomery, Alabama, in 1902 by Dr. Luther Leonidas Hill, Jr on a kitchen table with lights from kerosene lamps as their only light source. Thus learning from the history of medical science is of utmost importance for today's practitioners. Despite a myriad of advancements and new technologies in today's medical practice, some of the old 
treatments are being re-established and have been proved to be not so bad. ${ }^{8,9}$ Use of amniotic membranes to treat burns first in the early 1940s has now been re-stored to treat wounds. The old fashioned way of treating peptic ulcer by a vagotomy and pyloroplasty or gastric antrectomy is of course praiseworthy and noteworthy when modern medical measure fail to cure it. When modern Avant-grade endovascular attempts fail to revascularize an ischaemic organ, the relatively old fashioned open surgical by-pass graft approach can successfully revascularize it.

\section{References}

1. Anne-Emanuelle B, Raúl NL. Footprints on the Future: Looking Forward to the History of Health and Medicine in Latin America in the Twenty-First Century. Hispanic American Historical Review. 2011; 91 (3): 503-527.

2. Ian M. A Modern History of the Stomach: Gastric Illness, Medicine and British Society, 1800-1950, Routledge, 2015, 231-236.

3. Harley WJ, Janet A. Tighe, eds. Major Problems in the History of American Medicine and Public Health, NY, Boydell Press, 2006, 560.
4. Walter F, Magic W, Divination in Ancient Mesopotamia Civilizations of the Ancient near East New York: Charles Schribner's Sons, MacMillan Library Reference, Simon and Schuster MacMillan. 1891-908. ISBN 978-0-68419279-19276.

5. Hakim SZ. Studies in History of Medicine and Science, IHMMR, New Delhi, Vol. XIV, No. 1-2, 1996,1-39.

6. Kumar D, "India" in Roy Porter, ed, The Cambridge History of Science: Volume 4: 18th century Science, 2003, 680-683.

7. Cyrus DL. Quipus and Witches' Knots. Lawrence, Kansas: University of Kansas Press. 1967, 86-89.

8. Fred R. Hartesveldt V. The Doctors and the 'Flu': The British Medical Profession's Response to the Influenza Pandemic of 1918-19. International Social Science Review; 2010; 85 (1): 28-39.

9. Wright D. Getting Out of the Asylum: Understanding the Confinement of the Insane in the Nineteenth Century. Social History of Medicine. 1997; 10 (1): 137-155.
ABM Moniruddin

Professor of Surgery Member KYAMC Journal 